\title{
An exploratory study of South African women's experiences of In Vitro Fertilisation and Embryo Transfer (IVE-ET) at fertility clinics
}

\author{
Athena Pedro*, Kelvin Mwaba \\ Department of Psychology, University of the Western Cape, Bellville, South Africa; *Corresponding Author: aspedro@uwc.ac.za
}

Received 27 August 2013; revised 24 September 2013; accepted 6 October 2013

Copyright (c) 2013 Athena Pedro, Kelvin Mwaba. This is an open access article distributed under the Creative Commons Attribution License, which permits unrestricted use, distribution, and reproduction in any medium, provided the original work is properly cited.

\begin{abstract}
Infertility is considered to be a growing problem worldwide. In sub-Saharan Africa, at least $20 \%$ $50 \%$ of couples of reproductive age experience a fertility problem and $30 \%$ are diagnosed with infertility. This study explores the experiences of women in South Africa who are involuntary childless and explores their psychological and emotional experiences of In Vitro Fertilisation and Embryo Transfer (IVF-ET). Utilising a qualitative methodology, a diverse group of 21 married women diagnosed with infertility and who had undergone at least two cycles of IVF-ET were recruited. Semi-structured, in-depth individual interviews were conducted and the data were analysed using thematic analysis. The results of the study indicated that the women perceived themselves as not conforming to a dominant belief system and as a result felt compelled to explore all the medical options available. They reported emotional turmoil characterised by primary binary emotions of anxiety-excitement and nervousness-optimistic. These emotions were experienced throughout the five stages of the IVF-ET treatment cycles. A synopsis of the psychological and emotional responses to the IVF-ET treatment is discussed. The findings of this study suggest the need for the incorporation of a mandatory psychosocial intervention as part of infertility management. Greater attention to the psychological and emotional repercussions of infertility treatment could lead to a more personalised client-approach which, in turn, would prepare infertile women and couples for the emotional demands of the treatment.
\end{abstract}

Keywords: Infertility; In Vitro Fertilisation and
Embryo Transfer; Social Constructionist;

Psychological and Emotional

\section{INTRODUCTION}

Research in sub-Saharan Africa indicates that at least $20 \%-50 \%$ of couples of reproductive age, experience a fertility problem, and 30\% are diagnosed with infertility $[1,2]$. This is considered to be an exceptionally high statistic in comparison to other regions in the world [1-3]. The incidence of infertility in South Africa is estimated at $15 \%$ - 20\% [4]. In Cape Town, a culturally diverse, urban community in South Africa, approximately 1000 couples are referred to the Groote Schuur Hospital Infertility Clinic annually [5]. Since individuals may consult different specialist in private practice and not in public institutions where records are kept, reliable prevalence and incidence data may be difficult to obtain [6]. Lack of health services infrastructure may also attribute to the lack of estimations of infertility [7].

The underlying causes of the increased incidence of infertility in Africa are primarily the elevated incidence and prevalence of sexually transmitted infections (STI's), infections or complications following unsafe abortions and postpartum infections [1-3,5,8-10]. Data from a tertiary public health institution in South Africa showed that the leading causes of infertility were tubal factor infertility (diagnosed in 57\% of couples), male factor infertility (36\%), and anovulation (29\%) [11].

The aetiology of infertility is generally divided into four main categories, namely the female factor, the male factor, combined male and female factors and unexplained, idiopathic or psychosomatic infertility [12,13]. Male and female factors each account for $40 \%$ while the remaining $20 \%$ is either shared or unexplained factors $[14,15]$. However, the biomedical definition of infertility indicates how involuntary childlessness is located within discourses, which in turn informs the current under- 
standing of infertility and how it is responded to. Pregnancy is viewed as exclusively a female biological occurrence. In this light, prevailing discourses have presented biological reproduction as being associated with women's bodies, consequently fertility is viewed in terms of women, and infertility as her failure [16]. Since women are ultimately the ones to conceive and become pregnant, infertility is often regarded as a woman's problem whether or not the cause has been determined to be male factor infertility [1-3,8,17-19].

In many cultures, pregnancy and motherhood represent a profound developmental milestone that is highly revered [20,21]. Since South Africa is a pronatalist country, women often derive their value from their reproductive abilities [22-24]. Given that society places emphasis on motherhood, [25] childless individuals are often stigmatised $[5,26]$ as they are viewed as culturally deviant $[5,27]$. Pregnancy is perceived and accepted as a biological occurrence but motherhood is both biological and social [28-30]. Social constructs pertaining to motherhood culminates all the cultural elements that contribute to social roles and values attached to women in society [29,31].

Even though infertility is primarily dealt with medically, the psychological and emotional effects of infertility and infertility treatments are undeniable. Documented research suggests that about $40 \%$ of infertile individuals experience psychological distress associated with their condition [32]. Burns (1999) revealed that anxiety and major depressive episodes are the most commonly diagnosed psychiatric problems experienced by infertile individuals, and that this incidence tends to be higher in infertile women [33]. Domar, Zuttermeister and Friedman (1993) reported that infertile women presented with psychological distress levels similar to patients with terminal illnesses such as cancer, heart disease and hypertension [34].

This study explored the psychological experiences of involuntary childless women who have undergone at least two cycles of the In Vitro Fertilisation and Embryo Transfer (IVF-ET) treatment. The study adopted a social constructionist position which asserts that a particular reality does not exist, but rather that meaning is socially constructed through intrapersonal and interpersonal processes [35]. Translated to involuntary childlessness, the existence of a physiological impairment in one or both partners does not in itself determine how the individual or couple experience infertility. Rather, infertility relates to how individuals interpret, respond to and attach meaning to physical symptoms and psychological conditions [18].

\section{METHOD}

This study was placed within a qualitative methodo- logical framework as it provides personal descriptive accounts of how involuntary childless women experienced the In Vitro Fertilisation and Embryo Transfer (IVF-ET) treatment. These descriptive accounts provided in-depth insight into these women's thoughts, feelings and emotions of IVF-ET. The methodological framework is situated within the interpretivist framework where the role of language and discourse became central in the research process.

\subsection{Study Participants}

Criteria for participation was that women had to be married or in a committed relationship and at least have undergone two cycles of In Vitro Fertilisation and Embryo Transfer (IVF-ET). The snowball technique was used to recruit these participants. As potential participants were identified a screening questionnaire was used to determine whether these women matched the sample criteria. The participants selected were then invited to a briefing session whereby they were informed about the study aims, procedures and ethical considerations. When informed consent was provided the interview times and venues were then decided upon. The aim was to recruit a diverse sample of 30 women to participate in the study, however at the $21^{\text {st }}$ interview saturation point was reached.

\subsection{Data Collection and Study Instruments}

From the onset of the study it was decided that semistructured interviews would be appropriate for the study. The interview guide was developed and pretested to ensure content validity. Some of the questions that were modified related to the emotional (i.e. feelings) and psychological (i.e. thoughts) responses to IVF-ET and support required. Before each interview the participants were reminded that they were free to withdraw from the study at any time and that they did not have to answer questions that they deemed too personal or threatening. Each of the participants were handed a copy of the interview guide to peruse and explained how the interview process would unfold.

The interviews were generally structured into three phases; before the interview ("getting to know you better"), the interview ("tell me your story") and post interview ("tell me how you feeling"). The pre and post interviews were generally debriefing sessions. Each interview started with the pre-interview which was the first half an hour session. In this session, the idea was to build rapport; it was a general conversation between the interviewer and the participant. The second phase of the interview was the phase where the interviewer would create the space and ask the participant to "tell me your story".

The questions probed specifically about the In Vitro 
Fertilization and Embryo Transfer (IVF-ET) treatment. Some of the questions asked were "what made you decide to seek treatment, did you try to find information about the various treatment options available to you, when did you first find out about IVF-ET specifically and by whom, can you please describe the different phases of the IVF-ET process and what expectations did you have about the IVF-ET treatment”? Participants were also asked to describe their thoughts and feelings whilst undergoing treatment. The final phase of the interview involved a debriefing session. The purpose of these debriefing sessions was to alleviate the strain for the participants by talking about how they felt sharing their story and how they experienced the interview process.

\subsection{Ethical Considerations}

The ethical considerations adhered to in this study ranged from informed consent; minimization of potential harm/deprivation of benefits; and confidentiality and protection of privacy. All the participants were volunteers and gave written consent indicating that they understood the purpose of the study and were willing to share their experiences of infertility.

\subsection{Data Analysis}

The levels of analysis embarked on in this study were preliminary analysis, thematic analysis, coding, and interpretation. The first entry into analysis was to critically assess the data as it was collected, ascertain gaps in the information, and to commence with various concepts and establish a framework to assess if the data collected provided more information on issues relating to the research topic [36]. Each interview was read, summarized and analysed by means of developing themes. The themes that were established with the preliminary analysis were scrutinized once data had become saturated and an extensive view of the topic acquired. Each theme was placed in a specific file once it had been contextualised. There were essentially five major steps that made up the levels of analysis. The steps were; data organisation and reduction, thematic analysis, coding, interpretation and conclusion drawing.

\section{RESULTS}

\subsection{Demographics of the Sample}

A total of 21 women were recruited and participated in the study. The women ranged in age from twenty six to forty-one years. The average age of the participants was 30 years old. All of the participants are married 15 had a post-matric qualification, whereas the remaining six participants had a matric qualification. English was the first language for 16 of the participants, while three partici- pants were bilingual with both English and Afrikaans languages, and the remaining two participants spoke Afrikaans as a mother tongue. Only four of the participants were Muslim, the remaining 17 participants were all Christian in religion. About 19 of the participants are employed full time; only two of the participants are unemployed. While 12 of the participants were of the white race, nine participants were of the coloured race and one participant was a Christian Indian.

\subsection{Themes Identified}

The onset of the technological era has brought about many advances like ART but it has also presented new dilemmas. For instance, with the availability of the various fertility treatment options, infertile women are faced with great condemnation should they decide not to pursue ART; rejecting ART is denying oneself the opportunity for motherhood [37]. For many infertile women who choose not to use ART, it is often perceived that they are choosing to remain childless [37].

Some of the participants expressed this dilemma:

“When I think about it, if I don't try these treatments then its my own fault because I won't have a child if I don't try. On the other hand, it is so difficult to go through all of this and to find the money to pay for it".

"If we don't try it then we are effectively throwing away our chance to become parents to our biological children".

Participants expressed a strong belief in the success of the biomedical treatment options available to infertile women and couples. Some of these medical options included drug therapy, surgical procedures, and inseminations by the husband/donor, intra-uterine inseminations, and IVF-ET [38].

For the participants there were three main reasons motivating their pursuance of treatment; their strong desire to have their own biological child, their faith that medical treatment options were very real solutions to their infertility struggle and their trust in the expertise and supremacy of the doctors "playing God". The fertility treatment regimen comprises a range of medical procedures with IVF-ET usually being the last hope in the struggle of pursuing a biological baby [39].

\subsubsection{Optimism for IVF-ET}

The women in this study were very optimistic that the IVF-ET treatment would be successful. For many of the participants, this optimism stemmed from their desperation for a biological child and their belief in the medical fraternity and its technological advancements. Below are some of the comments of the participants.

"When you do look at your options available to you then naturally you turn to the medical route and you expect doctors to fix everything. When you are faced 
with having this want and this need of having your own baby it is something that is in you, part of you down to the core of your being, you will try anything. You will do anything it takes. IVF meant hope and excitement and to us it meant being able to have a baby".

"Initially, I remember saying to myself after the other treatments failed, everything will be fine and I will fall pregnant, I still have another option with IV". "When I was faced with the IVF treatment I was very hopeful. I was very confident that everything will be fine".

Participants shared their optimism and sense of hope that the IVF-ET would work. For the participants IVFET presented them with hope and optimism, excitement and joy because they were presented with another opportunity of achieving their goal of having a biological child. Whilst the participants were optimistic it was important to ascertain the understanding of the IVF-ET procedure.

\subsubsection{Knowledge of IVF-ET}

Participants displayed a good understanding of the IVF-ET procedure. They were asked to explain the IVF-ET treatment and the various phases. This question was asked to assess if the participants were aware of what the procedure entailed, and to assess how they behaved towards treatment. The rationale was to assess their response to treatment to ascertain whether they participated in the treatment regimen consciously aware and informed of what it entailed or if they participated "blindly," allowing the doctor and other medical personnel the leeway to perform the treatment. It was important to ascertain this information as it is indicative of the participants' perception of feeling in control and it highlights the participants' level of trust they have for the doctor as well as for the biomedical model of treatment. Some of the participants' responses below:

"At a particular point in your cycle then you're body's producing eggs, you get medication to increase your number of eggs. Once that part of the cycle was completed, the eggs are harvested, they're then fertilized in a lab, and then I think it's about three to four days, they implant it and you wait for 10 - 12 days to hear if your pregnant".

"Yes, the first phase was where I was given injections and the very low dosage initially, just to see how my body was going to respond and then I had to take those two injections simultaneously every day at a particular time or within the same time period and then I think about two weeks after that I went for a scan to check how many eggs my body was developing and then my body didn't respond very well, because my numbers were very low and the quality of my eggs was also not very good. Then thereafter we increased my dosage and still it didn't make much difference and then they removed the eggs from my body and fertilised it inside the lab and then a few days after that they put it back inside of me. It was unsuccessful".

It is evident from the above responses that the participants were well versed and familiar with the IVF-ET procedure. Generally, the participants were able to explain the procedure from the beginning to the end, prior to undergoing treatment.

"IVF is traumatic. Traumatic in the sense of it's a new form of medication. You have to take it every night at a specific time and needles... I don't like needles, it is horrible. The monitoring of the follicles and the blood, I had bloods done almost every day because they needed to check the hormone levels".

"I experienced it to be very upsetting and distressing. Because I needed to take these meds at specific times, I would be monitoring the time very closely and as the time got closer I would be getting more and more anxious for the needle-use. So it was a very unpleasant experience and I thought about it constantly as a result keeping me on edge all the time-definitely not a pleasant experience".

Some of the participants reported that one cannot really be prepared for the actual experience of blood tests, injections and scans. Knowing about it and actually experiencing it are two different experiences. These women expressed that the various phases in IVF-ET presented quite intense psychological strain. These participants experienced a variety of intense emotions, with clearly distinguishable highs and lows at different stages of the IVF-ET procedure. These highs and lows could be described as a roller coaster of intense emotions.

Despite being aware of what these treatment procedures entail, the intense emotions experienced by the treatment procedure may cause women undergoing the treatment to feel a sense of helplessness and therefore experience feelings of dyscontrol.

\subsubsection{Dyscontrol}

Dyscontrol was a very prominent theme among the women in this study. They expressed their frustration at their inability to control their fertility or reproductive inability. Compounding their frustration was having to rely on their doctors who were in control of the situation and their body, and yet unable to give a guarantee that the treatment will work. These women express the following:

“I remember asking him how long it's gonna take... I'm feeling very impatient. I like to get things done and I'm in control of everything, so, what... got to me the most was the fact that I wasn't in control of this".

"I'm one of those type A personalities you know, where you can't help yourself you just have to always 
be in control of things. And it was extremely difficult for me letting go of this and handing over my 'power' to other, especially someone I don't know and trust. But then you think to yourself it's a doctor, he knows what his doing".

These responses demonstrate how important it is for the participants to feel that they are in control of their lives, their bodies and their future. Since infertility may affect an individual's sense of control, they often express feelings of frustration and hopelessness. For many infertile individuals being part of the management of their infertility treatment is a means of asserting control (Mechanic, 1998).

\subsubsection{Experiences of the In-Vitro Fertilisation and Embryo Transfer (IVF-ET) Treatment Procedure}

The IVF-ET treatment procedure can be divided into five distinct phases; from stimulation of the ovaries to the waiting for the pregnancy result. These various phases with particular focus on the emotional and psychological responses to each of these phases will now be presented.

Pretext to Commencing IVF-ET: Participants were excited and hopeful about the prospects that IVF-ET held; an opportunity to experience a pregnancy. Whilst they had previously endured many trials of hormonal treatment with Clomid and a few failed cycles of intrauterine insemination/artificial insemination, they were still hopeful that IVF-ET may bring them success in their endeavours to conceive a healthy baby. These women expressed being "thankful" that they still had another option to try to conceive and felt that their chance of conceiving was good and that they were not just going through the motions of leaving their conception to chance. For the participants, it was a means of taking control of their infertility, control of their body and their situation [40].

When the participants were asked to describe how they felt approaching IVF-ET, they replied that they were "excited yet nervous and anxious about the medical aspect of having to do blood tests and scans" but felt that "what ever had to be done was worth it".

1) Phase (1) Stimulation of the Ovaries: The participants were given hormone injections to stimulate the ovaries so that multiple eggs are produced.

"It was tiring at one stage, because I remember the little bottles where you got to mix the powder with the water, when they calculated the time, I had to inject myself in the early hours of the morning and it actually tiring and had to remind myself, every day at this particular time I must have my injections, I mustn't forget”.

"Very traumatic and especially nerve wrecking for you and your husband, because you both have some expectations of the process, you are never really ready. You don't have a normal sex life for starters, because it is all in a schedule worked out for you".

The IVF-ET procedures can also be the source of stress and anxiety for many infertile women (couples) because it is a procedure which entails the patient injecting themselves at a specific time daily for a period of time, and undergoing close monitoring of hormone levels through ultrasound scans and blood tests.

"All the injections, your bums get so sore, believe me. It's been really nerve wrecking and you want to do everything right and perfect to make sure that you don't do something wrong to jeopardise it".

"The monitoring of the follicles and the blood, I had blood done almost every day because they wanted to monitor my hormone levels closely in case of hyper stimulation".

These women shared their experiences of injecting themselves and the monitoring of hormones through blood tests and ultrasound scans. Despite their dislike for needles they were still willing to proceed with treatment. This is an indication to what lengths many infertile people are willing to go to in order to achieve a pregnancy.

The women express how they felt during this particular phase.

"When you actually get over this needles and injections thing and of course the blood test and scans, I know it is a lot but believe it or not one get pass it if you do it often enough. The waiting for the eggs really made me anxious because we firstly had to check if the eggs will appear, then to check how many are appearing and then to see how many of these eggs matured, it all entails waiting, waiting, waiting".

"Each step has its own emotions because when we were waiting for the eggs to mature I was very anxious, nervous with a hint of excitement and anticipation. Then when the eggs are developed, anticipating the number of eggs, obviously the more the better, was also very exciting and at the same time also anxiety provoking. At this point optimism levels are rising because you can see yourself progressing to the next phase. Once you establish how many eggs you have and the number is sufficient, you become ecstatic, happy, so thankful and you feel so great".

The mixed emotions expressed in the first phase of treatment are evidence of the emotional impact of this procedure. These women expressed feeling anxious, nervous with a hint of excitement and anticipation for the eggs to develop. Once the eggs have matured, the next phase entailed the retrieval of the egg/s and this phase was described as being very exciting yet anxiety inducing.

2) Phase (2) Egg Retrieval: The women shared their 
experiences of this phase.

"In a way it was quite exciting but still nervewrecking. Exciting because they were going to remove the eggs and have them fertilised but nerve-wrecking because it is all so delicate and anything could go wrong at any time and there was nothing I could do to control any wrong or any risk".

"I was very nervous all the way because these eggs I prayed so hard for and went through so much for is going to be taken out and taken to a lab. Part of me is happy and excited because my eggs will get fertilised but I was too nervous to enjoy that part. I was feeling very optimistic about going to the next phase".

The above responses show how emotionally torn these participants were, in that they describe being nervous and anxious and yet excited and optimistic. The participants tended to approach IVF-ET on a phase-by-phase basis whereby they do not focus on the last phase or end result but rather on getting through one phase before focusing on the next phase. The participants were asked why they approached the IVF-ET procedure in this manner. The participants explained that their doctors worked in this manner, whereby every stage was dependent on the success of the previous stage, so approaching the IVF-ET procedure in this manner seemed logical and practical.

3) Phase (3) Fertilisation of Eggs and Sperm: Once the matured eggs have been retrieved, they are placed in a petri dish with a fluid and fertilised with the husband/partner's (donor's) sperm. This is a crucial stage of the IVF-ET process and all the hard work and commitment shown in the earlier phases has some sanctuary in the success of this phase. The participants shared their experiences of this phase with particular attention to how they felt during this phase of the IVF-ET.

"I was feeling very optimistic by this stage because things were successful with the other phases. I knew this phase was a biggy but I planned on being optimistic because I had good reason to be. In my mind I was cautiously optimistic but in my heart I just knew it was going to work".

"You know to tell you the truth I had mixed feelings. One minute I was optimistic and hopeful the next minute I was a complete nervous wreck totally overwhelmed by the process. Then I found myself being positive and actually feeling that this treatment can work, the next second I felt anxious, nervous, cautious. I couldn't keep up with the emotional turmoil".

The responses expressed by these women showed the intensity of emotions experienced as a result of the IVFET procedure. The participants felt happy with the success of the previous phases, but understood that the IVF-ET procedure was a process and that at any stage a problem could occur. Because of the "unknown", the participants found themselves emotionally bombarded between positive and negative feelings all the time from the beginning to the end.

"My emotions went up and down, like a rollercoaster. You get good news then you feel on top of the world and then its not so long then you get bad news and you literally fall to the bottom of the pit".

"With infertility treatment you have different stages and within these different stages you very often get good news or bad news, or and that's why you don't know how to feel and that's mixed emotion".

"You feel good when things are going as they should without focusing on the bad that could go wrong. So when its good news you absolutely thrilled and at times even feel a form of utopia like nothing can go wrong now everything is perfect. It's almost like your optimism breaks free and prevails till the next hurdle. But then at the same time you are aware that the negative could strike at any moment".

These women reinforce how emotionally cautious one should be because the optimism, hope and happiness one feels may be short lived and one should be aware that a bad experience may be imminent.

4) Phase (4) Embryo Transfer: About three days after the eggs have been fertilised, after the blastocyst stage has taken place. The laboratory technicians will decide if the embryos are ready to be transferred back into the womb. The participants were once again asked to describe how they felt during this phase of treatment. Participants described having mixed emotions.

“There wasn't one day when I can look back and say 'I remember having felt just sad or happy or hopeful'. Because in one day I felt nervous-excited, worried-optimistic all at once. I was nervous about the embryos being put back but excited at the same time. I was worried that something would go wrong, but at the same time I was optimistic that the procedure would be successful. Its crazy, I know but that was how it was".

"IVF can do things to you, that only IVF can. You are not yourself, your emotions are all over the place. The only feeling you are sure about is that you want your own baby and you will do anything to get it”.

These responses clearly demonstrate the intensity of the emotions felt. The participants describe experiencing feelings that rapidly change from one extreme to another. This phase of treatment is similar to the experiences described in the egg retrieval phase, where mixed emotions were apparent. Several women describe the emotional strain in this phase and reported that in one day having felt "nervous-anxious, worried-optimistic all at once". They described these emotions as being intertwined.

5) Phase (5) Waiting for Results: Once the embryos have been successfully transferred, the next phase is the 10 day waiting period to see if the embryo has implanted successfully. A blood test is taken 10 days later to verify 
if a pregnancy has successfully occurred [41]. Waiting has become a very prominent theme with infertility and infertility treatment. At every stage of the infertility journey, waiting occurs. For the participants, with waiting came anxiety, as having to wait for the results at every phase before being able to proceed to then next phase is very anxiety-inducing. However, the participants described the last phase; the 10-day waiting period as being the worst part of the procedure.

"I think that once you know what you have to go through and it is getting more bearable and now the most stressful moment of the treatment is when you get the final result. I think that one is the worst. The waiting can really make you very anxious, and you will sometimes think of all the bad things and this can really freak you out. I think the waiting for the results is the worst of all".

"I've dreaded each time that something would go wrong and each time we have really good news. But it is the waiting that kills you. It takes so much out of you that waiting, it makes you doubt yourself and your chances of success, it really affects you in a deep personal way".

Some of the women referred to the waiting as being what "kills you, takes so much from you, and makes you doubt yourself and your body". The intensity of the agony is evident and this phase of treatment demands a high level of self-dialogue, introspection and self-motivation. These women were asked to describe how they felt when they experienced a successful treatment outcome as well as an unsuccessful treatment outcome.

"Oh when the result is positive you are so happy and so relieved you won't believe it. It's like climbing this mountain and taking that last step to get to the top, oh it feels like heaven".

"When you hear that the IVF worked you immediately feel excited and you just want to dance and celebrate. It really felt good that it worked".

"It's just the worst thing in the world to put yourself through this and it doesn't work! You are devastated, heart-broken, you want nothing you don't want see anyone and just want to be left alone".

\section{DISCUSSION}

Women draw meaning and understand their childlessness from the values and norms of their socio-cultural context in which they live and function. Accordingly, women's decisions surrounding motherhood, infertility and ART are inextricably linked to the wider social structure. Pregnancy is perceived and accepted as a biological occurrence but motherhood is both biological and social [28-30]. For the participants in this study, it became evident that they live in a society that on the one hand pathologises infertility and on the other hand em- brace the dominant belief that the biomedical profession offers a cure and "promises" success. To this end, women enter treatment sometimes naively unaware of the psychological and emotional strain that accompanies these treatment procedures. These women enter into an almost blinding, addictive mode whereby their belief is focused on the "promised" success of treatment rather than on the reality of trauma associated with the treatment experience. Since these treatments are conducted on a cyclical basis, these women enter cycle after cycle without fully realising the extent of psychological trauma they are experiencing. The psychological strain of unsuccessful treatments is downplayed by the hope and optimism offered by the "anticipated" and "presumed" success of the next cycle.

Reproductive decisions are influenced by the social, economic and political structure of a society. It is difficult to accurately understand how, or to what degree, psychological ideologies and discourses, which formulate parenting as being an innate part of healthy development and motherhood as necessary to womanhood, have directly or indirectly influenced women's experiences and decision-making around infertility and its treatments. In addition, how this has impacted their frame of reference in terms of finding a solution. In trying to overcome infertility, many infertile women place themselves at great risk and are denied the opportunity of letting go of the desire to have a biological child until they have exhausted all of the options available to them. The participants described the IVF-ET treatment as being very distressing, painful or agonising and emotionally taxing. Whilst the psychological trauma and suffering are evident, there are no mandatory psychosocial support and counselling services available at infertility clinics. While some of the infertility clinics do have the services of a psychologist available, this is not the norm and the patient still has to cover the cost of the consultation themselves. The fertility clinics generally do not provide this support as part of the service of infertility management. The psychological effects of infertility and its treatments are hugely neglected by the medical practitioners at infertility clinics. Apart from the lack of psychological services provided, other forms of psychosocial support are also lacking. The participants in this study expressed the need to connect with other infertile people attending the fertility clinic so that through interaction they could compare and validate experiences, discuss various coping strategies and mechanisms and pose as a source of information and general support.

Fertility specialists and healthcare practitioners working at these fertility clinics may benefit from the findings of studies of this nature. The entire process of infertility is characterised by intense emotions culminating in feelings of hope and total devastation. Infertile women may find themselves having to negotiate these binary emo- 
tions all the time. Experiencing a range of these emotions simultaneously places women in a fragile psychological and emotional state and predisposes them to psychological difficulties. Future studies should extend the scope by investigating the psychological and emotional responses to IVF-ET of infertile couples and infertile men whilst undergoing the fertility treatment procedures. By highlighting and bringing to the fore the psychological difficulties experienced by infertile women undergoing fertility treatment and specifically the IVF-ET treatment, the specialists in the field may provide a more holistic treatment regimen that includes psychological support such as mandatory counselling. Since many fertility specialists are not trained in counselling or psychological management, the insight into the patients' emotional needs may prompt fertility clinics to employ a psychologist or psychological counsellor as part of the treatment regimen for the betterment of the client. This will also allow the patients to become more aware of the emotional cost that accompany these treatments, assisting them to employ more effective coping strategies whilst undergoing fertility treatments generally and more specifically the IVFET treatment.

\section{ACKNOWLEDGEMENTS}

We would hereby like to acknowledge the National Research Foundation for their financial assistance and co-funding of this study. There is no conflict of interest of any parties contributing to this study.

\section{REFERENCES}

[1] Inhorn, M.C. (1994) Interpreting infertility: Medical anthropological perspectives. Social Science and Medicine, 39, 59-461. http://dx.doi.org/10.1016/0277-9536(94)90089-2

[2] Okonofua, F. (1999) Infertility and women's reproductive health in Africa. African Journal of Reproductive Health, 3, 7-9. http://dx.doi.org/10.2307/3583224

[3] Van Balen, F. and Gerrits, T. (2001) Quality of infertility care in poor-resource areas and the introduction of new reproductive technologies. Human Reproduction, 16, 215219. http://dx.doi.org/10.1093/humrep/16.2.215

[4] Martin, A. (1997) Women's health project. Infertility: A literature review and annotated bibliography. Wits Press, Johannesburg

[5] Dyer, S.J., Abrahams, N., Hoffman, M., and van der Spuy, Z.M. (2002) Infertility in South African: Women's reproductive health knowledge and treatment-seeking behaviour for involuntary childlessness. Human Reproduction, 17, 1657-1662.

[6] Futeran, F.C. (1989) An exploratory study of the differences between a functional infertile, an organically infertile and a fertile group of married couples on the dimension of interactional functioning and mutual perceptions between partners. Unpublished Master's Dissertation. University of the Western Cape, South Africa.
[7] Sundby, J., Mboge, R. and Sonko, S. (1998) Infertility in the Gambia: Frequency and health care seeking. Social Science and Medicine, 46, 891-899. http://dx.doi.org/10.1016/S0277-9536(97)00215-3

[8] Abbey, A., Andrew, F.M. and Halman, J.L. (1991) Gender's role in responses to infertility. Psychology of Women Quarterly, 15, 295-316. http://dx.doi.org/10.1111/j.1471-6402.1991.tb00798.x

[9] Larsen, U. (2000) Infertility in central Africa. Tropical Medicine and International Health, 8, 354-367. http://dx.doi.org/10.1046/j.1365-3156.2003.01039.x

[10] Larsen, U. (2000) Primary and secondary infertility in sub-Saharan Africa. International Journal of Epidemiology, 29, 80-81. http://dx.doi.org/10.1093/ije/29.2.285

[11] Wiswedel, K. and Allen, D.A. (1989) Infertility factors at the Groote Schuur Hospital Fertility Clinic. South African Medical Journal, 76, 65-66.

[12] Cooper-Hilbert, B. (1998) Infertility and involuntary childlessness. W.W. Norton and Company Ltd., London.

[13] Davajan, V. and Israel, R. (1991) Diagnosis and medical treatment of infertility: Perspectives from Stress and Coping Research. 29-57.

[14] Eunpu, D.L. (1995) The impact of infertility and treatment. Guidelines for couple therapy. The American Journal of Family Therapy, 23, 115-128.

[15] Williams, M.E. (1997) Toward greater understanding of the psychological effects of infertility on women. Psychotherapy in Private Practice, 16, 7-28. http://dx.doi.org/10.1300/J294v16n03_02

[16] Riessman, C. (2000) Stigma and everyday resistance practices; childless women in South India. Gender and Society, 14, 111-135. http://dx.doi.org/10.1177/089124300014001007

[17] Abbey, A. (2000) Adjusting to infertilityloss and trauma: General and close. Relationship Perspectives, 331-344.

[18] Becker, G. and Nachtigall, R.D. (1994) "Born to be a Mother": The cultural construction of risk in infertility treatment in the US. Social Science and Medicine, 39, 507-518.

http://dx.doi.org/10.1016/0277-9536(94)90093-0

[19] Bliss, C. (1999) The social construction of infertility by minority women. Doctoral Dissertation.

[20] McEwan, K.L., Costella, C.G. and Taylor, P.J. (1987) Adjustment to infertility. Journal of Abnormal Psychology, 96, 108-116. http://dx.doi.org/10.1037/0021-843X.96.2.108

[21] Leke, R.J., Oduma, J.A., Bassol-Mayagoitia, S., Bacha, A.M. and Grigor, K.M. (1993) Regional and geographical variation in infertility: Effects of environmental, cultural and socioeconomic factors. Environmental Health Perspectives, 101, 73-80.

[22] Blenner, J.L. (1992) Patients' perceptions of infertility treatment. American Journal of Nursing, 41, 92-97.

[23] Savage, O.M. (1992) Artificial donor insemination in Yaounde: Some socio-cultural considerations. Social Science and Medicine, 35, 907-913. http://dx.doi.org/10.1016/0277-9536(92)90105-Y

[24] Sonko, S. (1994) Fertility and culture in sub-Saharan 
Africa: A review. United Nations Educational Scientific Certified Organisation, 141, 397-411.

[25] Venkatesan, L. (2005) Self-concept of infertile women. Nursing Journal of India, 96, 55-56.

[26] Beutel, M., Kupfer, P., Kehde, S., Kohn, F.M., SchroederPrintzen, I., Gips, H., Herrero, H.J.G. and Weidner, W. (1999) Treatment-related stresses and depression in couples undergoing assisted reproduction treatment IVF or ICSI. Andrologia, 31, 27-35

[27] Frediani, J.M. (1999) The effects of infertility on status and access to resources among Wamakonde women in Tanzania. Dissertation, University of California at Davis.

[28] Gordon, T. (1990) Feminist mothers. MacMillan Education Ltd., London.

[29] Green, Y.T. (2003) Women's health at the centers for disease control and prevention: A focus on prevention. Journal of Women's Imaging, 5, 47-51. http://dx.doi.org/10.1097/00130747-200305000-00001

[30] Sawicki, J. (1991) Disciplining Foucault: feminism, power, and the body. Routledge, Chapman and Hall Inc., New York.

[31] Goslinga-Roy, G. (2000) Body boundaries fiction of the female self: an ethnographic perspective on power, feminism, and the reproductive technologies.

[32] Burns, L.H. (1999) Psychology of infertility. In: Burns, L.H. and Covington, S.N., Eds., Infertility Counselling. Pathernon, New York.

[33] Morrow, K.A., Thoreson, R.W. and Penny, L.T. (1995)
Predictors of psychological distress among infertility clinic patients. Journal of Consulting and Clinical Psychology, 63, 163-167. http://dx.doi.org/10.1037/0022-006X.63.1.163

[34] Domar, A.D., Zuttermeister, P.C. and Friedman, R. (1973) The psychological impact of infertility: A comparison with patients with other Medical Conditions. Journal of Psychosomatic Obstetrics and Gynaecology, 14, 45-52.

[35] Burr, V. (1995) An introduction to social construction. London Routledge. http://dx.doi.org/10.4324/9780203299968

[36] Grbich, C. (1999) Qualitative research in health. An introduction. Sage, London.

[37] Marshall, H. (1993) Not having children. Oxford University Press, Australia.

[38] Royal Commission on New Reproductive Technologies. (1993) Proceed with care. Final report of the royal commission on new reproductive technologies summary and highlights. The Commission, Ottawa.

[39] Reproductive Health Network (2003) Reproductive Health Network. http://www.reproductivehealth.net/

[40] Mechanic, D. (1998) Public trust and initiatives for new healthcare partnerships. The Milbank Quarterly, 76, 281302. http://dx.doi.org/10.1111/1468-0009.00089

[41] Daniluk, J.C. (2001) "If we had it to do over again..." Couples' reflections on their experiences of infertility treatments. The Family Journal: Counselling and Therapy for Couples and Families, 9, 122-133. 